\title{
THE EFFECTS OF AUTOCATALYTIC TRADE CYCLES ON ECONOMIC GROWTH
}

\author{
Jurriën J. Bakker ${ }^{1}$, Oscar Afonso ${ }^{2}$, Sandra T. Silva ${ }^{3}$ \\ ${ }^{1}$ Managerial Economics, Strategy and Innovation (MSI), Faculty of Economics and Applied \\ Economics, K.U. Leuven, Naamsestraat 69 bus 3500, B 3000 Leuven, Belgium \\ ${ }^{2}$ CEFUP, OBEGEF, NIFIP, Faculty of Economics, University of Porto, \\ Rua Roberto Frias, s/n, 4200-464 Porto, Portugal \\ ${ }^{3}$ CEFUP, Faculty of Economics, University of Porto, Rua Roberto Frias, \\ $s / n, 4200-464$ Porto, Portugal \\ E-mails: 1j.j.bakker@student.tue.nl; 20afonso@fep.up.pt (corresponding author); \\ 3sandras@fep.up.pt
}

Received 09 March 2012; accepted 09 August 2012

\begin{abstract}
This paper shows that autocatalytic trade cycles can be a positive feedback system for innovation and thus for economic growth. Using United Nations data, a trade network is proposed and a set of variables that represent the participation of countries in autocatalytic trade cycles is constructed. A clear relationship between these variables and economic growth is found since more innovation is produced in countries that are part of trade cycles. However, the relationship changes with autocatalytic trade cycle sizes, categories of goods and time scales. Moreover, autocatalytic trade cycles also have a positive effect for the trade flows involved, although this effect differs significantly depending on the size of the cycles. This new approach based on autocatalytic trade cycles emphasizes the benefits that countries can extract from trade cycles and points out the need of policies that foster these benefits. These conclusions strengthen existing literature, and also add new insights to innovation policy and the pursuit of economic prosperity.
\end{abstract}

Keywords: R\&D; innovation; technological knowledge; economic growth; autocatalytic trade cycles; international trade; policy.

Reference to this paper should be made as follows: Bakker, J. J.; Afonso, O.; Silva, S. T. 2014. The effects of autocatalytic trade cycles on economic growth, Journal of Business Economics and Management 15(3): 486-508.

JEL Classification: C3, F1, O3.

\section{Introduction}

Innovation is essential to technological-knowledge progress, which, in turn, is an engine of economic growth (Gil et al. 2013.). Hence, most countries should be interested in ways to improve their technological-knowledge competence.

The causes for innovation are often best reviewed in a competitive framework: entities, such as governments and firms, that innovate, are expected to fare better than ones 
which do not innovate (Werker 2003). However, this may not be the only reason to innovate: Cassell (2008) found that their decision to innovate was dependent on more factors than simply to save costs.

A traditional way of innovating is through research and development (R\&D) efforts. Empirical evidence of this growth mechanism has been shown in, for example, Lichtenberg (1993) and Coe and Helpman (1995). At the theoretical level, the first-generation of comprehensive, well articulated general equilibrium growth models based on R\&D that seek to explore the role of technological knowledge change in the economic growth process, are centred on two types of R\&D processes - horizontal and vertical.

In the first one, $\mathrm{R} \& \mathrm{D}$ is directed at developing new horizontally differentiated goods, an approach followed in prominent works by Romer (1986, 1990), Rivera-Batiz and Romer (1991), Grossman and Helpman (1991) and Barro and Sala-i-Martin (2004). Since there are no quality advances, no good ever becomes obsolete. Firms that become producers remain leaders from then on without further R\&D effort, since they are granted a patent that lasts forever.

In the vertical process, $R \& D$ is instead directed at developing new vertically differentiated qualities of each good, an approach that was first developed by Segerstrom et al. (1990), Grossman and Helpman (1991), and Aghion and Howitt (1992). The resulting models are called Schumpeterian (inspired by the Schumpeterian concept of creative destruction), or quality ladder models, since, assuming that the leadership of the firms that use the state-of-the-art qualities is only temporary - permanently subject to destruction by new qualities resulting from successful R\&D.

Hence, when integrated in endogenous growth models, R\&D activities - either horizontal or vertical - result in technological-knowledge progress, which, in turn, is the primary determinant of growth. Two major characteristics of technological knowledge are essential for its role as an endogenous engine of growth - non-rivalry and partial non-excludability. Technological knowledge is non-rival in the sense that the marginal costs for its use by an additional firm are negligible; and it is partially non-excludable since the returns to private investment in its production are partly private and partly public. As a result, the total return on innovation for the society as a whole (the social return) is greater than the private return.

As a result, in general, it is considered decreasing returns to R\&D (e.g. Ha, Howitt 2007). The phenomenon of decreasing returns to R\&D means that innovating becomes more and more costly as measured in $R \& D$ costs per increase in quality of goods or decrease in factor inputs. This is often caused by the exhaustion of technological paradigms that the R\&D effort has taken place in so far (e.g. Dosi 1982). However, Madsen (2007) has suggested that decreasing returns to R\&D cannot always be easily found.

To overcome this problem a new technological paradigm needs to be found. In fact, one needs to innovate more radically. Here, radical innovation is not limited to a particular good or service strictly deviating from the path it has taken so far, being defined as deviating enough to start improving a good at a reasonable R\&D efficiency again. This 
kind of innovation is distinct from the incremental type, which does not involve new paradigms - e.g. Dosi (1982) and Freeman (1991).

For countries that are not leaders (some developed and developing countries), the first major way of overcoming the problem of decreasing returns to R\&D is by imitating innovations from leaders. When successful, imitation allows for the technologicalknowledge difusion embodied in a good, as the imitator reverse-engineers that good. Imitation is often a less costly process than innovating: Mansfield et al. (1981) reports that the cost of imitation is, on the average, about $65 \%$ of the cost of innovation. Thus, imitation will be often the best choice for follower countries to catch up (Afonso 2012, 2013; Motohashi et al. 2012). However, the imitating process on its own does not bring innovation in a global system; it only aids its diffusion (Afonso 2012, 2013).

Moreover, the existence of spillovers is not sufficient for diffusion and catching up by the follower countries. In fact, diffusion requires the followers to absorb the technological-knowledge spillovers; i.e. to have the capacity to incorporate the innovative spillovers in their own R\&D. Imitation capacity is enhanced by domestic policies promoting R\&D (e.g. Aghion et al. 2001), by the degree of openness and other trade policies (e.g. Coe et al. 1997), and decreases with the human-capital gap in relation to the leaders (e.g. Nelson, Phelps 1966). In the presence of imitation capacity, the advantage-of-backwardness assumption is observed. This assumption considers that the rate of technological-knowledge progress in the followers is an increasing function of the gap between their own technological-knowledge level and that of the leaders (e.g. Barro, Sala-i-Martin 1997; Afonso 2012, 2013).

The combination of old ideas and concepts into new ideas, or recombination, is often a successful strategy for innovation (e.g. Galunic, Rodan 1998). A good strategy is to collaborate with other partners in order to promote exchanges between their distinct knowledge stocks.

International trade can play a major role by aiding the recombination of ideas and concepts. Trading also allows for a more efficient knowledge flow in general (e.g. Coe et al. 1997; Afonso 2012). Recombination often occurs when goods are imported. It can lead to a variety of not only adapted goods, but also entirely new uses. Besides, having recombination by the importer, problems can be discussed in different contexts and techniques for production can be learned from abroad to the advantage for exporting firms (e.g. Silva et al. 2013).

Recently most research in the area of international trade and innovation is focused on the effects of export, which are important indeed. The export-space (types of goods that are exported) of a country is a good predictor for new export (e.g. Hidalgo et al. 2007). Export variety is important for economic growth (e.g. Saviotti, Frenken 2008). Firms that start to export are learning faster than firms that do not (e.g. Silva et al. 2013).

Imports account for economic growth as well since they provide essential factors for production and allow for the transfer of knowledge that can be used to improve production and to foster innovation (e.g. Bayoumi et al. 1999). The easiest way that import can contribute to local innovation is by aiding imitation, especially for less-developed countries (e.g. Afonso 2012). 
Still, even a view that considers both imports and exports could be too limited. First, because international trade does not occur only as an independent bilateral experience since trade relations are mutually dependent. Thus, a network approach could be valuable. In this line, Shih et al. (2009), instead of purely bilateral indicators, as bilateral import and export parameters, considered the centrality of countries in the trade network as a measure for diffusing technological knowledge.

Moreover, technological knowledge that comes from trade import is likely to decline over time if the relation is only one-sided. This is because less and less new ideas, goods and processes can be transferred, since the unused technological knowledge is decreasing. Over time the technological knowledge import would be scaling with the technological knowledge production in the exporting country. And, since its production faces decreasing returns to $\mathrm{R} \& \mathrm{D}$, this flow of new knowledge probably dries up as well.

To overcome these problems and to keep on innovating, a self-enforcing, or autocatalytic, process needs to be instated. An autocatalytic system will create exponential returns due to its positive feedback mechanism. Positive feedback mechanisms are possible only when there is a cyclical nature to information within a system. After all there needs to be a feedback, which implies that information of any activity is related back to the source. The notion of cyclical autocatalytic processes is not new and is often derived from chemistry and ecology (e.g. Matutinović 2005).

Combining the notion of autocatalytic cyclical processes with the importance of trade to innovation provokes the question: Could autocatalytic trade cycles be a positive feedback system for innovation? The nature of innovation suggests they can: innovation will be more persistent if it occurs in a cyclical system. This is because in a cycle there will be a continuous recombination of knowledge stocks, which should then lead to continuous innovation. This way of technological-knowledge production does not face decreasing returns since technological paradigms will be often shifted. As discussed above, trade is conducive, not only to copying and diffusing technological knowledge but also to producing innovation itself. Hence, it seems that autocatalytic trade cycles produce continuous innovation. If that is true then the partners of these autocatalytic trade cycles will experience more economic growth than otherwise.

This discussion leads to the main research question of this paper: is it beneficial, in terms of economic growth, for a country to be part of an autocatalytic trade cycle? If this is true, then innovating and creating economic growth while being part of an autocatalytic trade cycle should be more efficient than innovating outside of a cycle. Thus, this indicates the follow up question: is it possible to develop a policy that takes advantage of autocatalytic trade cycles? If the results from the first research question allow policy implications to be derived, then the question can be answered positively. However if the results from the first research question are more ambiguous this will not be possible.

The remainder of this paper will provide an answer to these two research questions. In the following section the research questions will be more elaborated on by stating hypotheses that relate to these questions. When testing these hypotheses, answers to the research questions can be provided. In Section 2, the methodology for testing the 
aforementioned hypotheses will be explained. Section 3 discusses the results of these tests. General policy recommendations based on these results are provided in Section 4. Finally, the conclusions of this work on autocatalytic trade cycles will be shown, based on a comparison between the answers to the first and the second research questions.

\section{Hypotheses}

To investigate the research questions a new approach is proposed to capture different economic aspects. It was chosen because, at present, there has been no research on autocatalytic trade cycles.

For studying different autocatalytic trade cycles it is important to define the length of such a cycle, which will be defined by the number of countries that are involved in it. The hypotheses relate to the effects of autocatalytic trade cycles on the economic performance of the involved countries. These hypotheses will start at the relation between autocatalytic trade cycles and general economic performance, and then move to the different cycles per good category, and will finally consider the length of the autocatalytic trade cycles.

The first research question is related to the idea that countries that are part of autocatalytic trade cycles can economically benefit from it. Hence, the following hypothesis is considered:

H(i): Countries that are part of autocatalytic trade cycles experience more economic growth than countries which are not. If it is beneficial to be part of an autocatalytic trade cycle then over time trade connections that constitute an autocatalytic trade cycle will be more likely to grow than connections that do not constitute autocatalytic trade cycles: the innovation that should occur will likely increase the trade flow. Since this happens more in autocatalytic trade cycles, trade flows that constitute these cycles will be growing faster. Therefore, a second hypothesis is put forward:

H(ii): In a trade network, the trade flows that constitute autocatalytic trade cycles are relatively higher than flows that are not part of an autocatalytic trade cycle. Since the autocatalytic trade cycle argument revolves around innovation, it is expected that more good categories which are experiencing major changes due to innovation will have more important autocatalytic trade cycles. Since these changes are not spread equally through time and good categories, the importance of autocatalytic trade cycles will vary across these two parameters. This brings up two additional hypotheses:

H(iii.1): The importance of autocatalytic trade cycles will vary for different categories of goods and times.

H(iii.2): The autocatalytic trade cycles from innovative goods will be more important to the economic growth than the autocatalytic trade cycles from less innovative goods. 
However, not all autocatalytic trade cycles have to bring in an equal amount of economic growth. One would expect that the length of a cycle is an important factor. Since innovation often occurs due to the recombination of ideas, one would expect longer autocatalytic trade cycles to be more conducive to innovation. Nonetheless, for novelty to occur it needs to fit in with the socio-economic system in which the innovation is taking place. The more different the socio-economic system is the less likely the innovation will fit and thereby the performance of goods will deteriorates. This holds true even for high-tech goods (e.g. Getler 1995). Thus, a better fit of an innovation is more likely to happen with shorter cycles, as ideas and practices get less affected by other systems. When combining these two aspects, a trade-off is expected. But the results of this trade-off might be different for distinct categories of goods, relying on the innovation that is happening at that time in the category. Hence:

H(iv): There is an optimal length at which autocatalytic trade cycles are most conducive to economic growth. This optimal cycle length may vary per category of goods.

\section{Methodology}

\subsection{The trade network}

The methodology for testing the hypotheses is based on extracting cycles from the international trade data in the National Bureau of Economic Research (NBER) database (Feenstra et al. 2005). This database lists all international trade flows, documented by the United Nations (UN) from 1962 to 2000. The trade flows are listed by category of goods on the basis of the Standard Industrial Classification in four digits (SIC 4). After the collection of data, the autocatalytic trade cycles are calculated for ten different classes of trade, indicated by the first digit of the SIC 4 classification. This is done per year over the period from 1962 to 2000.

The main decision here is to consider which trade flows are relevant: if all trade flows are included, the trade network will be too dense to have a relevant measure of the number of autocatalytic trade cycles. Therefore, the less important trade flows need to be excluded from the analysis. To assist this procedure a quality measure $q_{i, j}$ for a trade flow $t_{i, j}$ from country $c_{i}$ to $c_{j}$ with value $v_{i, j}$ will be introduced:

$$
q_{i, j}=\frac{v_{i, j}}{\operatorname{MINTRADE}\left(c_{i}, c_{j}\right)} .
$$

In (1), MINTRADE is an operator which picks the minimum sum of the imports and exports of the countries involved. This sum of imports and exports is also referred to as a measure of openness for a given economy if it is divided by Gross Domestic Product (GDP). It was decided not to divide it by GDP since the inclusion of GDP in the selection process would mean that openness of the economy would be a major factor influencing the number of links per country.

Since this paper deals mainly with the structure of the network it is better to make the selection process based mostly on the trade volume per country. This means, from a network perspective, that selection is solely based on the property of the links, regard- 
less of the properties of the nodes. Hence, with a substantial reduction of links, most nodes will be more equal in their number of links in the trade network. This occurs because nodes with a large number of links will lose more links than nodes with a small number of them, since the quality of the links will be lower when a node has a larger number of links. Moreover, this means that here the autocatalytic trade cycles refer to the structure of the trade per node. It does not value more open economies more than more closed economies. There is also the advantage that trade flows involving countries with very open economies (e.g. because they are at a trade nexus such as Singapore and the Netherlands) will be not be weighed disproportionally.

To choose the minimum quality value qmin from which trade flows are admitted, the following reasoning is used: to assert a relative independence for countries who are part of autocatalytic trade cycles it is important that their autocatalytic trade cycles do not overlap too much. A key measure for this is the average path length of the trade network related to the cycle length. If the average path length is shorter than the cycle length most countries will share at least one autocatalytic trade cycle. Thus, the cycle length cannot exceed the average path length too much.

The network that is used sometimes includes countries that are not part of any cycle. If they were included in the measure for the average path length, this measure would be distorted. This is because they contribute with their lower connections to a higher average path length. Hence, the countries that are in autocatalytic trade cycles are connected more than the average path length indicates. To omit this problem an adjusted measure for average path length is used in which these countries are excluded. To estimate the average path length $l$ the formula as derived in Fronczak et al. (2004), for a random network with $N$ nodes and a distribution of $k$ links per node is used:

$$
l=\frac{-2<\ln k>+\ln <N>+\ln <k(k-1)>-\gamma}{\ln N+\ln <k(k-1)>-\ln \beta}+\frac{1}{2} .
$$

In $(2), \gamma \approx 0.5772$ is Euler's constant while $\beta$ is a constant depending on the kind of distribution of links we expect. It will be assumed that the distribution corresponds roughly to that of an Erdos-Renyi random network with a Poisson distribution. ${ }^{1}$ The validation of this is that, as mentioned earlier, most nodes are becoming more equal in the amount of links. Within the trade networks in study, often a large portion of links (75-90\%) needed to be deleted in order to achieve the desired average path length. Therefore, this procedure negated most of the original distribution of links per node, resulting in a Poisson distribution. This was validated by examining the distribution of links in a number of different trade networks after a significant reduction of low quality links. With this distribution $\beta$ would have the following value: $N<k>$.

From Fronczak et al. (2004) it seems this formula underestimates $l$ slightly for low $N\left(N \sim 10^{2}\right)$; this is not a problem since the average path length sets a maximum for the

1 This is a network with the underlying assumption that the chance of a link existing between two nodes is equal for all nodes. This is unlike, e.g. a scale free network, where this is dependent on the number of links a node already has. Erdős and Rényi (1960) have shown that the distribution of links in a random network follows a Poisson distribution. 
cycle length, hence a slight underestimation of this parameter will lead to results that are more reliable than needed. The following procedure is applied: the minimum quality value qmin is raised, thus allowing more flows to be deleted until the required average path length is achieved. Occasionally this procedure leads to an empty network, because the required average path length could not be achieved. In this case the network with the highest average path length, which has appeared in the previous procedure, will be chosen. These path lengths are often very close to the required average path length. Judging from the likely values for $N$ and the distribution of $k$, the highest average path length that can be obtained, while still including most countries, is 2 . This indicates that the maximum cycle length that can be measured is a cycle including 4 countries.

\subsection{Determining the effect of autocatalytic trade cycles on economic growth}

The process of determining the effect of autocatalytic trade cycles will yield 6 indicators per category of goods, which combines magnitude of autocatalytic trade cycles per each length of the autocatalytic trade cycle per se. In this case there are cycles with 2, 3 and 4 countries. The magnitude of an autocatalytic trade cycle is defined here as its circulation value, or as the lowest value of the trade flows that it consists of. The 6 indicators are probably highly correlated, since the likelihood of a country being in a cycle with 4 countries grows as the number of cycles with 3 countries, involving that country grows. As a result, a multiple regression with all indicators as independent variables will suffer from multicollinearity. To overcome this problem, a factor analysis will be used to reduce these 6 indicators into 1 or 2 composite variables, depending on the outcome of the analysis.

Because of the nature of the selection process, the major confounding variables here are imports and exports, as they will probably influence the trade flows that were chosen in the trade network and they will also have an effect on economic growth. The third confounding variable to consider is GDP since it can be assumed that countries with different GDP levels will have different trade structures, e.g. a core periphery structure in the world economy. GDP will also affect GDP growth because different sized economies will grow at different rates. These variables will be used to predict economic growth as measured in the relative increase of real GDP. ${ }^{2}$ Because it is expected that innovation processes operate on timescales larger than a year and on different timescales for different goods, time series for the 10 different goods will be constructed. In these time series the composite variables will estimate both the annual rate of GDP growth and the rate of aggregate GDP growth for consecutively more years ahead.

\subsection{Determining the effect of autocatalytic trade cycles on trade}

To test hypothesis (ii) the number of autocatalytic trade cycles that a certain trade flow is in will be determined. Due to the selection process of the trade network a comparison between flows that are in or out of autocatalytic trade cycles cannot be made. This is because trade flows that are not in the network are by definition smaller than flows that

2 GDP data was obtained from the World Bank. 2011.[Online], [cited January 2012]. Available from Internet: http://www.worldbank.org. 
are in the trade network, since small trade flows will have a higher chance of being deleted than larger trade flows.

Therefore, in order to test hypothesis (ii), a comparison will be made between the number of autocatalytic trade cycles a trade flow is in and its value. Since there are 3 different sizes of cycles there will be 3 different indicators. With these indicators a multivariate linear regression with the trade value as a dependent variable will be run. Unfortunately, the problem of multicollinearity is harder to solve because there are less indicators; however, the problem will be also smaller due to the same reason.

\subsection{Determining the effect of autocatalytic trade cycles in different categories of goods}

Hypotheses (iii.1) and (iii.2) suggest that the autocatalytic trade cycles associated with different goods will have different effects on economic growth. To test for this, the 6 indicators, for the combined value and number of 2, 3 and 4 sized autocatalytic trade cycles, will be used to compare the effects for each category of goods. These categories are based on the first digit from the SIC 4 classification (Table 1).

A high correlation will be expected in these indicators for the same reason as described in Section 2.2. Thus, the same process of using factor analysis to extract 1 or 2 composites out of these 6 indicators will be used. The main comparison will be made on the normalized effect of the composites on growth. This effect will be determined using multivariate linear regressions, with the same confounding variables as mentioned in Section 2.2. A time series approach will be used because there is no a priori assumption on the typical timescale of innovation. This holds even more for different goods categories. It can be seen if autocatalytic trade cycles from different categories of goods have different effects on different timescales.

\subsection{Determining the effect of autocatalytic trade cycles of different lengths}

Hypothesis (iv) deals with the effects of different lengths. Indicators of autocatalytic trade cycles of different lengths are often highly correlated. If this is the case it is not possible to compare the effects of different lengths of autocatalytic trade cycles in that particular category of goods. However, if the indicators are not highly correlated, testing hypothesis (iv) becomes a possibility. If the abovementioned indicators do not correlate very well, the factor analysis will show it. Hence, the same set of composite indicators and regressions can be used to test this hypothesis for a limited set of goods.

\section{Results}

\subsection{Hypothesis (i): the effects of autocatalytic trade cycles on GDP growth}

This hypothesis deals with the effect of autocatalytic trade cycles on GDP of the countries involved. The country to country trade data was used to create a network out of which the autocatalytic trade cycles could be calculated. The factor analysis that followed indicated that two separate variables were needed to represent the indicators from the autocatalytic trade cycles: variable 1 to represent data mostly from the 2 and the 3 sized cycles and variable 2 to represent the 4 sized cycles. 
Table 1. Broad classification of the different categories of goods

\begin{tabular}{cl}
\hline Category & \\
\hline SIC 0 & Agriculture, fishing and forestry \\
\hline SIC 1 & Mining and construction \\
\hline SIC 2 & Light manufacturing \\
\hline SIC 3 & Heavy manufacturing \\
\hline SIC 4 & Infrastructure and communication \\
\hline SIC 5 & Retail and wholesale trade \\
\hline SIC 6 & Services (financial) \\
\hline SIC 7 & Services (personal and business) \\
\hline SIC 8 & Services (health, legal, educational, cultural, social and consulting) \\
\hline SIC 9 & Public administration
\end{tabular}

Results from the linear regressions with GDP per year as a dependent variable, and in years following, are depicted in Figure 1. For variable 1 there is a strong and significant correlation between the indicator and GDP increase per year. It also appears that there are two timescales: one of about 2-3 years later and other of 9 years later. Variable 2 seems to have an insignificant and small effect. Only at 2 and 6 years there is a significant effect which could point to a certain timescale, but since that effect is quite small this is not a robust finding.

Results from the regressions with aggregated GDP over a certain amount of years (see Fig. 1) confirm the previous findings: variable 1 has a significant impact on GDP growth for all time periods, while variable 2 is mostly small and insignificant. From the time scales for variable 1 only the scale around 11 years is visible in the aggregated GDP regressions. The 6 year time scale of variable 2 becomes more insignificant, while
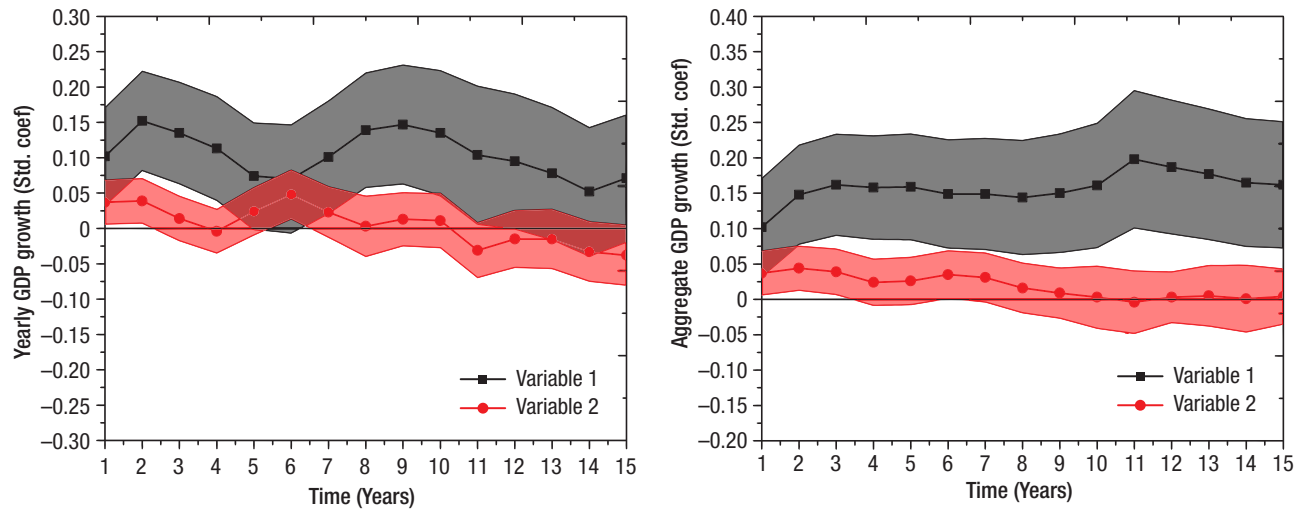

Fig. 1. Relation between the time scale and the standardized coefficients for the composite variables

Notes: The composite variables represent the trade cycles for the aggregated trade between countries. Shaded areas depict a 95\% confidence interval. 
the 2 year time scale is still significant. But since there is relatively little difference between the graphs on small time scales this could be expected. Results of the regressions indicate a significant relation between the amount, both in value and number, of autocatalytic trade cycles and GDP growth. Thus the hypothesis should be accepted.

\subsection{Hypothesis (ii): the effect of autocatalytic trade cycles on trade flows}

In this hypothesis the effects of being part of autocatalytic trade cycles on the size of the trade flows is examined. If the hypothesis is to be accepted there should be a significant positive effect of being in an autocatalytic trade cycle for a trade flow. In total 1.241.627 trade flows were included to test this hypothesis.

The covariance matrix shows that there is a reasonable, but small correlation between the dependent variable and the 3 indicators (Table 2). Unfortunately the correlation between 3 and 4 sized cycles is very large. This means that their respective coefficients are less reliable; this is compensated for by the large number of cases that could be examined.

Table 2. Covariance matrix depicting the correlation between the independent and dependent variables in the linear regression

\begin{tabular}{lcccc}
\hline Correlation & Trade value & $\begin{array}{c}\text { Nr. of 2 sized } \\
\text { cycles }\end{array}$ & $\begin{array}{c}\text { Nr. of 3 sized } \\
\text { cycles }\end{array}$ & $\begin{array}{c}\text { Nr. of 4 sized } \\
\text { cycles }\end{array}$ \\
\hline Trade value & 1 & 0.0716 & 0.1578 & 0.1129 \\
\hline Nr. of 2 sized cycles & 0.0716 & 1 & 0.5087 & 0.5135 \\
\hline Nr. of 3 sized cycles & 0.1578 & 0.5087 & 1 & 0.9267 \\
\hline Nr. of 4 sized cycles & 0.1129 & 0.5135 & 0.9267 & 1 \\
\hline
\end{tabular}

Table 3. Results of the linear regression with the value of the trade flow as a dependent variable

\begin{tabular}{lccccc}
\hline & \multicolumn{2}{c}{ Unstandardized coefficients } & Standardized coefficients & Significance \\
\hline & Value & Standard deviation & Value & Standard deviation & \\
\hline Constant & -30165 & 896 & 0 & 0 & 0 \\
\hline Nr of 2 sized cycles & 2296 & 1384 & 0.00157 & 0.001014 & 0.097 \\
\hline Nr of 3 sized cycles & 50955 & 313 & 0.377 & 0.0023 & 0 \\
\hline Nr of 4 sized cycles & -238 & 2.33 & -0.237 & 0.0023 & 0 \\
\hline
\end{tabular}

Results of the linear regression in Table 3 indicate that there is a significant relationship between the value of a trade flow and its presence in one or more cycles. However, the relationship differs for different sized cycles. Being in a 2 sized cycle has no significant effect on the trade flow. Being part of a 3 sized cycle however, does have a major and significant effect on the size of the flow. Being in a 4 sized cycle has a significant negative relationship to magnitude of the trade flow. 
Looking at the standardized coefficients, it is possible to see that being in more autocatalytic trade cycles is overall positive for the value of a trade flow. However, the size of the trade flow is a significant variable to consider.

\subsection{Hypothesis (iii): the importance of autocatalytic trade cycles from different categories of goods}

Now the independent variables are the autocatalytic trade cycles per category of goods. The first part of the hypothesis states that autocatalytic trade cycles in different categories have different effects on GDP growth. The second part of the hypothesis states that the effect on GDP growth should be more profound for more innovative goods.

To test this hypothesis the following method was used: first different trade networks were made for different goods; second the autocatalytic trade cycle indicators were calculated for each country; then factor analyses were made to determine the composite variables for each category of good; finally two series of regressions were made, one with GDP growth per year in $x$ years following, and another with aggregated GDP over $x$ years as dependent variables.

Since there were 10 categories of goods tested, only a few results will be discussed in detail here. These results should provide a clear picture of the overall trends. From the other categories a short summary will be made.

\subsubsection{Results from some categories of goods}

Results that will be discussed in detail are from the following categories of goods: SIC 2, SIC 4 and SIC 9. ${ }^{3}$ These categories were chosen because they represent either a group of categories, (SIC 2 and SIC 9) or are unusual compared to the other categories (SIC 4).

Regarding the results from category SIC 2 (see Fig. 2), the factor analysis indicated two variables. Variable 1 , mainly dealing with $2 \& 3$ sized autocatalytic trade cycles and variable 2, mainly dealing with 4 sized autocatalytic trade cycles. The results of the year on year growth of GDP show that there is a significant relation between variable 1 and year on year GDP growth for the entire time span of 15 years, although the strength is decreasing over time. The inverse is true for variable 2 , which is strongly and significantly negative for most values and also decreasing over time. The results from year on year GDP regressions are confirmed by the aggregate GDP growth. These series show a stable and significant relation from both variables with aggregate GDP growth.

The category of goods of SIC 4 had the following characteristics (see Fig. 3): the factor analysis indicated two variables, as was the case in SIC 2. Variable 1 included all indicators (variable 1), while variable 2 only contained the numbers of cycles (variable 2). The year on year regressions show that variable 1 has a small and mostly insignificant relation to the dependent variable. There are two significant timescales: a negative for the first 3-4 years and a positive for a timescale of roughly 11 years. Variable 2 is mostly positive and significant except for the time scale of 11 years, which could be ex-

3 Descriptions of the categories are given in Table 1. 

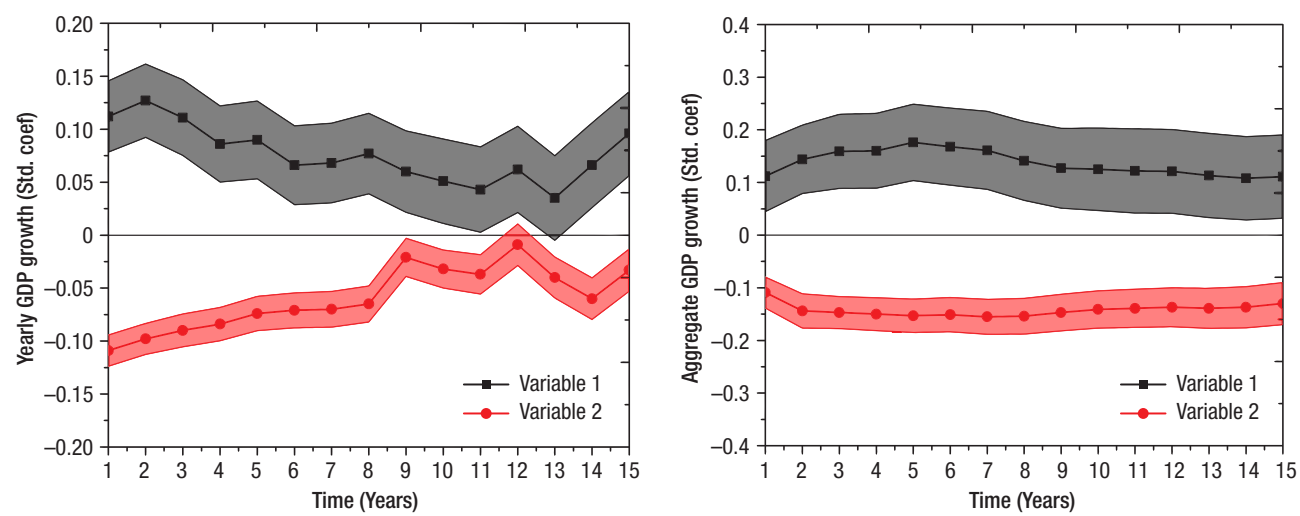

Fig. 2. Relation between the time scale and the standardized coefficients for the composite variables Notes: composite variables represent the trade cycles for category SIC 2. Shaded areas depict a $95 \%$ confidence interval
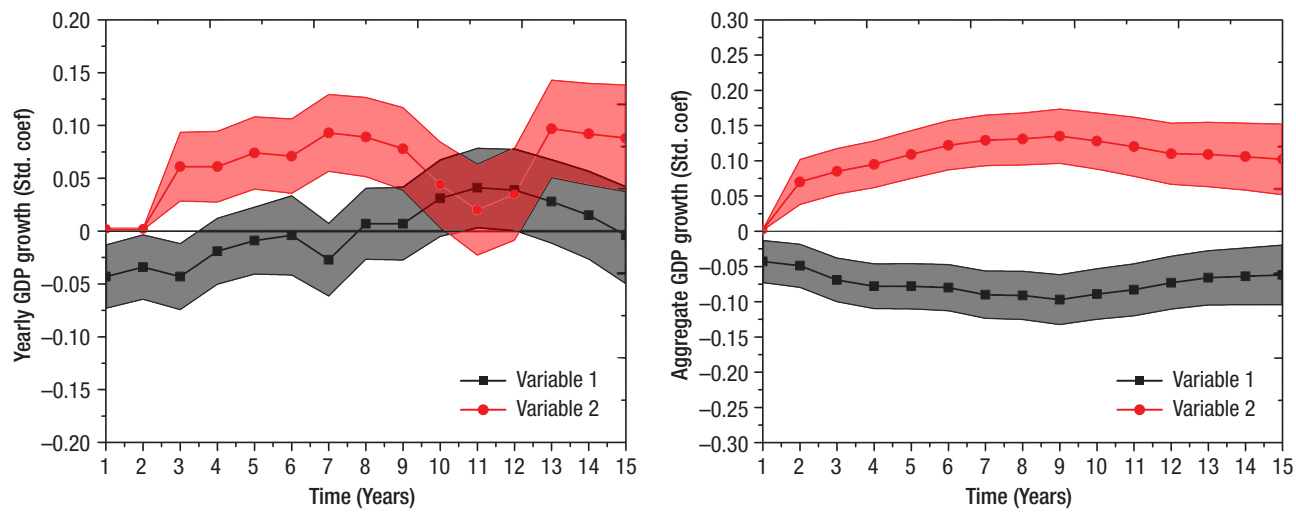

Fig. 3. Relation between the time scale and the standardized coefficients for the composite variables

Notes: composite variables represent the trade cycles for category SIC 4. Shaded areas depict a $95 \%$ confidence interval

plained by the rise in the coefficient of variable 1 . The results from the regressions with the aggregate GDP growth show a more clear result: variable 1 is negative, strong and significant related to the aggregate GDP growth, while variable 2 is the inverse of this.

The category of goods of SIC 9 had the following results (see Fig. 4): the factor analysis was inconclusive over the amount of variables to be included. Since variable 2 had no interpretable relation to the autocatalytic trade cycle indicators, it was decided to include only one variable. The standardized coefficient of the variable for regression for year on year GDP growth is positive and significant with a maximum at a 7 year timescale and a minimum around an 11 year time scale. The results from the series of regressions with aggregate GDP growth show a clear maximum around 7 years, indicating a 7 year time scale, while also at other time scales showing continuously positive significant results. 

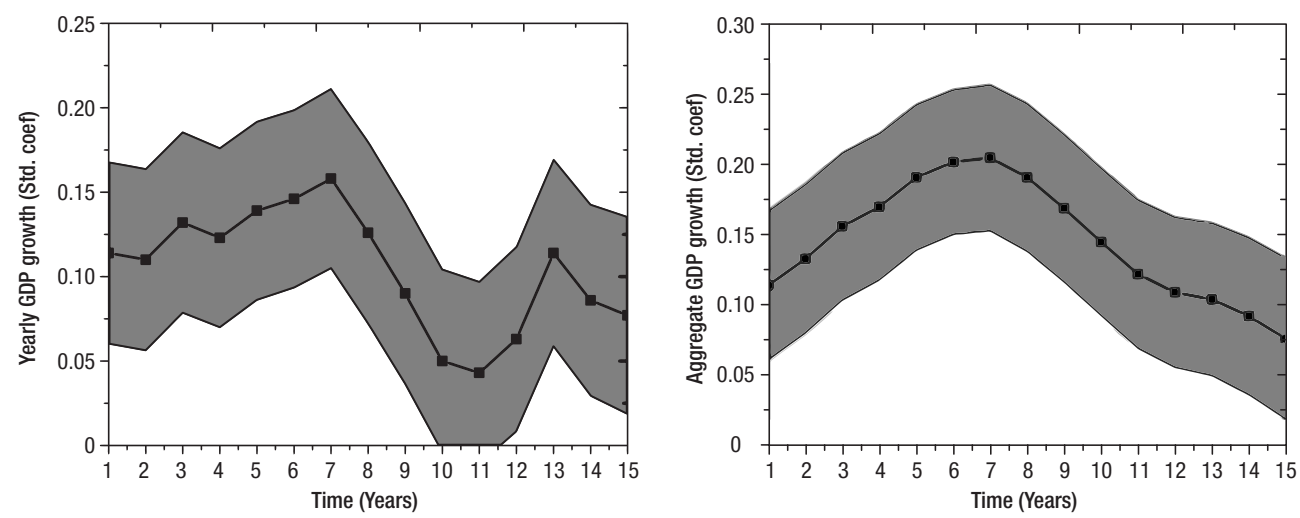

Fig. 4. Relation between the time scale and the standardized coefficients for the composite variables Notes: composite variables represent the trade cycles for category SIC 9. Shaded areas depict a $95 \%$ confidence interval

\subsubsection{Summary of the results for the other categories of goods}

Results from the other categories of goods could be gathered into three different groups: the first group has categories similar to SIC 2 with two variables representing respectively $2 \& 3$ sized cycles and 4 sized cycles. This group contains SIC 0 and SIC 8. Furthermore, the second group is similar to SIC 9 and has one variable representing all indicators. SIC 3 and SIC 7 are represented in here. Finally, the last group had insignificant results for all variables that were tested and consists of SIC 1 and SIC 5, and SIC 6.

The group similar to SIC 2 contains the following categories of goods: SIC 0 and SIC 8. In both of these categories variable 1 is positively related to GDP growth on a year on year basis, while variable 2 is insignificant but mostly negative for most of the time span. Variable 1 for both SIC 0 and SIC 8 has significant results for the time scales of 2 and 9 years. In the analysis of aggregate GDP growth variable 2 is significantly negative for both categories. Variable 1 is constant and almost significant for SIC 0 and only significant at a time scale of 3 years for SIC 8.

In the second group, which is similar to SIC 9, there is only one variable to represent all of the autocatalytic trade cycle indicators. This group consists of SIC 3 and SIC 7: on a yearly basis the coefficients from both categories are mostly insignificant. It is mostly positive for SIC 3, while SIC 7 gives a more mixed view. On the aggregate GDP growth the variable from category SIC 3 has a significant, but not very strong, relationship with the dependent variable. This relationship has its maximum at roughly 7 years. The variable from the SIC 7 category has a continuously positive relationship with a significant maximum at a time scale of around 3-4 years. After that maximum the relation becomes insignificant for the remainder of the timescales.

\subsubsection{Conclusion}

In the majority of the 10 examined categories, there was a significant relationship between the composite variable and the GDP growth. This relation differs per category, and per time scale (see Table 4). 
Table 4. Overview of regression results per goods category

\begin{tabular}{|c|c|c|c|c|}
\hline Category & Description & $\begin{array}{c}\text { Contents composite } \\
\text { variable }\end{array}$ & $\begin{array}{l}\text { Relation to aggregated } \\
\text { GDP growth }\end{array}$ & $\begin{array}{c}\text { Typical } \\
\text { times cale (s) }\end{array}$ \\
\hline \multirow[t]{2}{*}{ SIC 0} & \multirow{2}{*}{$\begin{array}{l}\text { Agriculture, fishing } \\
\text { and forestry }\end{array}$} & $2 \& 3$ sized cycles & Non-significant positive & $\mathrm{n} / \mathrm{a}$ \\
\hline & & 4 sized cycles & Significant negative & $\mathrm{n} / \mathrm{a}$ \\
\hline SIC 1 & $\begin{array}{l}\text { Mining and } \\
\text { construction }\end{array}$ & All indicators & Significant negative & $3-$ \\
\hline \multirow[t]{2}{*}{ SIC 2} & \multirow[t]{2}{*}{ Light manufacturing } & $2 \& 3$ sized cycles & Significant positive & $5+$ \\
\hline & & 4 sized cycles & Significant negative & $\mathrm{n} / \mathrm{a}$ \\
\hline SIC 3 & Heavy manufacturing & All indicators & Significant positive & $7+$ \\
\hline \multirow[t]{2}{*}{ SIC 4} & \multirow{2}{*}{$\begin{array}{l}\text { Infrastructure and } \\
\text { communication }\end{array}$} & Value of cycles & Significant negative & 9- \\
\hline & & Number of cycles & Significant positive & $9+$ \\
\hline SIC 5 & $\begin{array}{l}\text { Retail and wholesale } \\
\text { trade }\end{array}$ & All indicators & Non-significant positive & $\mathrm{n} / \mathrm{a}$ \\
\hline SIC 6 & Services (financial) & All indicators & Non-significant & $2(+), 13(-)$ \\
\hline SIC 7 & $\begin{array}{l}\text { Services (personal } \\
\text { and business) }\end{array}$ & All indicators & Significant positive & $2+$ \\
\hline \multirow[t]{2}{*}{ SIC 8} & Services (other) & $2 \& 3$ sized cycles & Significant positive & $3+$ and $9+$ \\
\hline & & 4 sized cycles & Significant negative & $9-$ \\
\hline SIC 9 & Public administration & All indicators & Significant positive & $7+$ \\
\hline
\end{tabular}

Notes: significance at the 0.05 level for a number of years. Timescale indicates extremes in the relation of the variable with aggregate GDP growth. + is a positive maximum and - is a negative minimum. When no clear extreme was observed, this is denoted by $\mathrm{n} / \mathrm{a}$.

The categories with the strongest relation between their respective autocatalytic trade cycles and GDP growth were manufacturing, transport and governmental services. Therefore, it seems that industries, where large capital investments need to be made, profit more from autocatalytic trade cycles than industries without those requirements. This does not fully correspond to hypothesis (iii.2). However, since the goods categories were fairly broad, this warrants further investigation.

\subsection{Hypothesis (iv): the optimal length of an autocatalytic trade cycle}

Hypothesis (iv) states that there is an optimal size of an autocatalytic trade cycle and that this optimal length probably varies for different categories of goods.

The optimal length of an autocatalytic trade cycle was hard to verify since the lengths of autocatalytic trade cycles are highly correlated (Table 3 ). However, for a number of distinct categories of goods there was a comparison possible between $2 \& 3$ sized autocatalytic trade cycles, on the one hand, and 4 sized autocatalytic trade cycles, on the other hand.

These categories were SIC 0, SIC 2, SIC 8 and the overall trade between countries. The variables representing $2 \& 3$ sized autocatalytic trade cycles were consistently posi- 
tively related to GDP growth, while the variables representing 4 sized autocatalytic trade cycles were consistently negatively related to GDP growth. Therefore, for these categories the optimal length of autocatalytic trade cycles is either 2 or 3 . The results from hypothesis (ii) indicate that this optimal autocatalytic trade cycle length is more likely to be 3 than 2 .

For the other categories this optimal autocatalytic trade cycle length is probably larger than 3. However, this is hard to test for since it was impossible to test for larger autocatalytic trade cycles. Thus, it is plausible that an optimal autocatalytic trade cycle length exists and that this is different for different categories. Therefore, hypothesis (iv) is validated.

\section{General policy recommendations}

This section will serve as a bridge between the hypotheses dealing with the effects of autocatalytic trade cycles, and the implementation of these results.

A number of different policies can be implemented to benefit from the effects of autocatalytic trade cycles, as discussed in Section 3. They can be either to change the composition of the economy into more profitable sectors for autocatalytic trade cycles, or to promote the strengthening of already existing autocatalytic trade cycles. The different measures shall be better discussed.

\subsection{Changing the composition of the economy}

Results in Section 3 show that generally being a part of an autocatalytic trade cycle is beneficial for growth. Indeed, Section 3.3 describes how different goods have different effects. The largest effects were registered in manufacturing, both light and heavy, infrastructure, personal services and (semi-) public goods. However, the effects had often mixed components. This was the case in light manufacturing, infrastructure and semi public goods (SIC 8). Thus, the effects are reduced in these sectors. That leaves heavy manufacturing, services and the governmental sector. Since the governmental sector is hardly associated with export/import, and this relation does not seem to be caused by a direct effect, heavy manufacturing and services are the sectors that can be promoted.

This selection of sectors leaves two different policies with two different effects. For a sustained long term effect it is better to support heavy manufacturing, which will result in a growth that maximizes about 7 years later but will make effects relatively early and constant. For a more direct effect, it is better to support the services industry, which has a maximum effect in 2 years, but this effect will dissipate quite soon.

It has to be noted that heavy manufacturing requires strong investments in capital and, since this has a lag in itself, results may take a long time to be visible. However, the development of a services industry should not be taken lightly since it will require a significant investment in human capital, which could take a long time to accumulate as well. 


\subsection{Changing regulations with respect to trade}

Open economies will be more likely to be part of autocatalytic trade cycles. However, this paper is related more to the structure of trade flows rather than to the openness of economies (see Section 2.1). Hence, just being more open does not mean that autocatalytic trade cycles are automatically beneficial. However, it is important to be open in sectors in which these autocatalytic trade cycles are present. The sectors that are most likely to contribute to economic growth are heavy manufacturing and services (see Section 4.1). This does not mean that opening the economy for other sectors is wrong. The autocatalytic process described in the introduction could work in any industry. This process will probably function better when the goods are more innovative. This was tested with hypothesis (iii.2), but since the tested categories were too broad, this could not be fully verified. This reasoning suggests that a country should focus to be open in industries that are innovative and that can profit from international cooperation.

Making the economy more open can be done by reducing trade barriers on both the export and the import sides of a sector. Foreign entities often have the possibility to add more innovation to goods than domestic industries. However, this openness should not destroy the domestic industry, for without it the capacity to adapt to foreign innovations, or adoptive capacity (Arrow 1969), will be reduced.

\subsection{Forging trade connections}

Results of Section 3 suggest that forming autocatalytic trade cycles is beneficial for economic growth. This is mainly true for small sized cycles. Thus, a possibility to involve foreign policy presents itself.

Foreign policy can aid the forming of autocatalytic trade cycles by promoting domestic goods and services in other countries. This can create innovation and thereby economic growth back home as was indicated by Saviotti and Frenken (2008) and Silva et al. (2013). But not only the export side should be facilitated; promoting the internal market to foreign companies could also be a worthwhile endeavour. The research by Bayoumi et al. (1999); Coe and Helpman (1995) indicates that trade imports support imitation and domestic innovation. This is especially true when foreign companies start adapting their products and services to the internal market, thereby contributing their own innovations to domestic goods. When the trade connection is formed through both imports and exports, it can lead to the creation of autocatalytic trade cycles.

Industrial policy can also aid forming new autocatalytic trade cycles: industries should be more focused towards markets from which the policy-maker knows he/she can learn and which will return the business directly or indirectly. Also cooperation with importing and exporting firms abroad can help to start new autocatalytic trade cycles. This creation would occur in a similar but more direct way than the process in this paragraph.

\subsection{Making existing autocatalytic trade cycles more autocatalytic}

Existing autocatalytic trade cycles can also be made more autocatalytic by providing facilities for trading companies to discuss changes and problems with their suppliers 
and customers in other countries. The more problems and solutions can be diffused the more ideas and more innovation can be created (Thompson 1965). Making autocatalytic trade cycles more autocatalytic can be done by directly bringing suppliers, firms and clients more in touch with each other. Firms often have too little an idea of whom they are dealing with, and can profit more by sharing common problems (Dyer 1996). The government can facilitate these gatherings by promoting factory visits by foreigners, and by promoting visits abroad. It also should provide a service to analyse where problems and miscommunication between international partners persist since cultural and language differences can make these trade cycles less autocatalytic (Getler 1995).

This should also include future customers, suppliers and domestic firms. However, this procedure may not be an easy task since most of the information related to innovation is often proprietary, a trade secret or patented. Thus, firms will be often reluctant to cooperate to a full extent to an open sharing of information, unless there is a large degree of trust between the sharing firms (Kale et al. 2000).

The solution can be the creation of a forum in which trade problems can be discussed, presenting opportunities for companies to innovate without giving away too much information. The more open this forum is, the more players can inform themselves and either present solutions or innovate to supply better goods. Furthermore, an open exchange can produce trust so that firms are willing to share more information. Hence, all players will benefit.

\section{Conclusions}

In this paper the effects and implications of autocatalytic trade cycles have been discussed. Autocatalytic trade cycles are cycles that are conducive to innovation for the countries involved. The literature on innovation suggested that autocatalytic trade cycles could be formed by countries in an trade cycle. Since innovation translates into economic growth, autocatalytic trade cycles should be an indicator for this growth.

For these research questions several hypotheses were formed. These hypotheses were tested with UN trade data over the period 1962-2000, obtained via the NBER. This data was filtered using an approach which worked by selecting trade flows. This meant that the selection process was blind to the total openness of a country, which allowed looking more into the effects of the structure of the trade network.

The above methodology allowed the construction of indicators which represented the value and number of three different sized autocatalytic trade cycles. One or two variables were formed from these indicators, dependent on the results of a factor analysis. These variables were then be used to test the hypotheses. It was confirmed that the first variable from the autocatalytic trade cycles in the general trade network correlated significant and positively with GDP growth. The second variable was mostly negative but insignificant. This confirmed the hypothesis that autocatalytic trade cycles correlate positively with GDP growth. 
The second hypothesis was that trade flows that are being a part of more autocatalytic trade cycles are bigger than trade flows that are part of less autocatalytic trade cycles. The trade flows that were used to test this were all part of at least one autocatalytic trade cycle. The results of the linear regression showed that only being a part of more 3 sized trade cycles was significantly positive related to the size of a trade flow. Being part of a 4 sized cycle was found to be significantly negative related to this size.

Results confirmed that the effects of autocatalytic trade cycles differ significantly for different categories of goods. Three goods categories showed a significant positive relation with GDP growth: heavy manufacturing, personal services and public administration. Another three categories had one variable out of the two that related positively and significantly to GDP growth: light manufacturing, infrastructure and another section of services. The testing of the second part of the hypothesis was less conclusive: It was likely, but not certain that more innovative categories of goods would profit more from autocatalytic trade cycles. The categories of goods were too broad to confirm this hypothesis.

The fourth hypothesis could also be validated with the help of the results from testing hypotheses (ii) and (iii). It was confirmed that an optimal autocatalytic trade cycle length probably existed and that, for most categories of goods, this optimal length was likely to be 3. A general policy recommendations could be made: among others, more direct cooperation with foreign governments, as well as opening certain markets for trade.

This paper has shown in general that autocatalytic trade cycles are having a significant effect on economic growth, thereby answering the main research question.

However, a central issue with variables related to the total trade network is that parameters of single countries are always externally affected by actions of other countries. Thus, it is impossible to completely separate the measures on ego networks from the total network configuration, even when strict requirements on average path length are being fulfilled. Another consideration, which is related to the study of countries over the years, is that these countries are interconnected on several other parameters. This means that the success or failure of economic policy needs to be always seen as being partially dependent on the success and failures of others. This is true in times of global recessions and global economic booms.

Next to these general considerations a more specific issue was encountered when reviewing the indicators of autocatalytic trade cycles. This review yielded often two variables: One significantly positive associated with GDP growth; and one significantly negatively associated with GDP growth. While it was expected to see a divergence in the effect of differently sized autocatalytic trade cycles as hypothesis (iv) indicated, the negative association with GDP growth was unexpected. This indicates that autocatalytic trade cycles have negative effects on GDP growth. An explanation for this is that longer autocatalytic trade cycles bring more competition, while not contributing as much to local innovation. 
Future work could focus on better understanding the effects of autocatalytic trade cycles and producing more tailored advice. As the results from hypotheses (iii.2) and (iv) have shown, the categories of goods are still very broad and it would be important to know if the results still hold on a more detailed level. Furthermore, the effects of autocatalytic trade cycles, and that of different goods, may differ on a variety of parameters of the countries involved. For example: the development level, the amount of human capital, the types of industrial activities, and the geographical location of the country. Another aspect that is worth looking into is what the effects are of different partners of the autocatalytic trade cycles.

Also, it would be important to see how autocatalytic trade cycles influence other variables besides GDP growth, such as the human development index, employment or one of the several innovation variables. Autocatalytic cycles can also occur within the borders of a single nation, especially when this nation has a large differentiated economy (e.g. the USA). A research on the effects of autocatalytic trade cycles between different sectors within an economy could help to understand better the effects of autocatalytic trade cycles, because it reduces the effects of culture, language and geography in these cycles. It would be interesting to see the relationship between the optimal length of an autocatalytic trade cycle and these three parameters. From a policy perspective it would also be interesting to see if autocatalytic trade cycles could be used in the same way as exports are used in Hidalgo et al. (2007). This means that the presence of a country in an autocatalytic trade cycle could be an important indicator for the industry of that particular country. Finally, it is relevant to understand that this research has been undertaken on a macro scale. The precise workings of autocatalytic trade cycles are still unknown. It would be important to understand under what conditions these cycles form and which actors are involved.

In conclusion, to the best of our knowledge, this paper is the first one to discuss the effects and implications of autocatalytic trade cycles. It is interesting to see that a variable, like autocatalytic trade cycles, has such a relation with GDP growth. This is even more interesting since there is no a priori reason for the effects observed, other than the autocatalytic trade cycle argument provided in this paper. The results also provide a further insight in the ways that innovation is operating. This highlights the importance on studying and using innovation to improve economic growth and to improve the general welfare of societies. It would therefore be a worthwhile endeavour to research this subject in depth, using the results of this subfield to improve the welfare of our societies.

\section{References}

Aghion, P.; Howitt, P. 1992. A model of growth through creative destruction, Econometrica 60(2): 323-352. http://dx.doi.org/10.2307/2951599

Aghion, P.; Harris, C.; Howitt, P.; Vickers, J. 2001. Competition, imitation and growth with stepby-step innovation, Review of Economic Studies 68(3): 467-492.

http://dx.doi.org/10.1111/1467-937X.00177

Afonso, O. 2012. Scale-independent North-South trade effects on the technological-knowledge bias and on wage inequality, Review of World Economics 148(1): 181-207.

http://dx.doi.org/10.1007/s10290-011-0109-7 
Afonso, O. 2013. Diffusion and directed technological knowledge, human capital and wages, Economic Modelling 31: 370-382. http://dx.doi.org/10.1016/j.econmod.2012.11.011

Alesina, A.; Spolaore, E. 1997. On the number and size of nations, Quarterly Journal of Economics 112(4): 1027-1056. http://dx.doi.org/10.1162/003355300555411

Arrow, K. 1969. Classificatory notes on the production and transmission of technological knowledge, American Economic Review, Papers and Proceedings 59(2): 29-35.

Barro, R. J.; Sala-i-Martin, X. 2004. Economic growth. 2nd ed. Cambridge, MA: MIT Press.

Bayoumi, T.; Coe, D.; Helpman, E. 1999. R\&D spillovers and global growth, Journal of International Economics 47: 399-428. http://dx.doi.org/10.1016/S0022-1996(98)00018-X

Cassell, M. 2008. Why governments innovate: adoption and implementation of open source software by four european cities, International Public Management Journal 11(2): 193-213.

http://dx.doi.org/10.1080/10967490802095680

Coe, D. T.; Helpman, E. 1995. International R\&D spillovers, European Economic Review 39(5): 859-897. http://dx.doi.org/10.1016/0014-2921(94)00100-E

Coe, D. T.; Helpman, E.; Hoffmeister, A. 1997. North-south R\&D spillovers, Economic Journal 107(440): 134-149. http://dx.doi.org/10.1111/1468-0297.00146

Dosi, G. 1982. Technical paradigms and technological trajectories: a suggested interpretation of the determinants and directions of technical change, Research Policy 11(3): 147-162.

http://dx.doi.org/10.1016/0048-7333(82)90016-6

Dyer, J. 1996. Specialized supplier networks as a source of competitive advantage: evidence from the auto industry, Strategic Management Journal 17(4): 271-291. http://dx.doi.org/10.1002/ (SICI)1097-0266(199604)17:4<271::AID-SMJ807>3.0.CO;2-Y

Erdős, P.; Rényi, A. 1960. On the evolution of random graphs, Hungarian academy of sciences 5: 17-61.

Feenstra, R. C.; Lipsey, R. E.; Ma, H.; Mo, H. 2005. World trade flows: 1962-2000, National Bureau of Economic Research (NBER) Working paper series 11040 [online], [cited January 2012]. Available from Internet: http://www.nber.org/papers/w11040

Freeman, C. 1991. Innovation, changes of techno-economic paradigm and biological analogies in economics, Revue Economique 42(2): 211-231.

Fronczak, A.; Fronczak, P.; Hołyst, J. A. 2004. Average path length in random networks, Physical Review 70: 56-110.

Galunic, D. C.; Rodan, S. 1998. Resource recombinations in the firm: knowledge structures and the potential for schumpeterian innovation, Strategic Management Journal 19: 1193-1201. http://dx.doi.org/10.1002/(SICI)1097-0266(1998120)19:12<1193::AID-SMJ5>3.0.CO;2-F

Getler, M. S. 1995. Being there: proximity, organization, and culture in the development and adoption of advanced manufacturing technologies, Economic Geography 71(1): 1-26.

http://dx.doi.org/10.2307/144433

Gil, P. M.; Brito, P.; Afonso, O. 2013. Growth and firm dynamics with horizontal and vertical R\&D, Macroeconomic Dynamics 17(7): 1438-1466.

http://dx.doi.org/10.1017/S1365100512000181

Grossman, G. M.; Helpman, E. 1991. Innovation and growth in the global economy. Cambridge, MA: MIT Press.

Ha, J.; Howitt, P. 2007. Accounting for trends in productivity and R\&D: a schumpeterian critique of semi-endogenous growth theory, Journal of Money, Credit and Banking 39: 733-774. http:// dx.doi.org/10.1111/j.1538-4616.2007.00045.x

Hidalgo, C. A.; Klinger, B.; Barabosi, A.-L.; Hausmann, R. 2007. The product space conditions the development of nations, Science 324: 317-482. 
Kale, P.; Singh, H.; Perlmutter, H. 2000. Learning and protection of proprietary assets in strategic alliances: building relational capital, Strategic Management Journal 21(3): 217-237.

http://dx.doi.org/10.1002/(SICI)1097-0266(200003)21:3<217::AID-SMJ95>3.0.CO;2-Y

Lichtenberg, F. 1993. R\&D investment and international productivity differences, in H. Siebert (Ed.). Economic growth in the world economy. Tubingen: J. C. B. Mohr. 89-110.

Madsen, J. 2007. Are there diminishing returns to R\&D?, Economics Letters 95(2): 161-166. http://dx.doi.org/10.1016/j.econlet.2006.09.009

Mansfield, E. M.; Schwartz; Wagner, X. 1981. Imitation costs and patents: an empirical study, Economic Journal 91(364): 907-918. http://dx.doi.org/10.2307/2232499

Matutinović, I. 2005. The microeconomic foundations of business cycles: from institutions to autocatalytic networks, Journal of Economic Issues 39(4): 867-898.

Motohashi, K.; Lee, D.; Sawng, Y.; Kim, S. 2012. Innovative converged service and its adoption, use and diffusion: a holistic approach to diffusion of innovations, combining adoption-diffusion and use-diffusion paradigms, Journal of Business Economics and Management 13(2): 308-333. http://dx.doi.org/10.3846/16111699.2011.620147

Nelson, R.; Phelps, E. 1966. Investment in humans, technological diffusion, and economic growth, American Economic Review 56: 69-75.

Rivera-Batiz, L.; Romer, P. 1991. Economic integration and endogenous growth, Quarterly Journal of Economics 106(2): 531-555. http://dx.doi.org/10.2307/2937946

Romer, P. 1986. Increasing returns and long-run growth, Journal of Political Economy 94(2): 1002-1037. http://dx.doi.org/10.1086/261420

Romer, P. 1990. Capital, labor, and productivity, Brookings Papers on Economic Activity (Microeconomics Special Issue): 337-367.

Saviotti, P.; Frenken, K. 2008. Export variety and the economic performance of countries, Journal of Evolutionary Economics 18: 201-218. http://dx.doi.org/10.1007/s00191-007-0081-5

Segerstrom, P. S.; Anant, T. C. A.; Dinopoulos, E. 1990. A schumpeterian model of the product life cycle, American Economic Review 80(5): 1077-1091.

Shih, H.; Tung-Lung, X.; Chang, S. 2009. International diffusion of embodied and disembodied technology: a network analysis approach, Technological Forecasting \& Social Change 76: 821-834. http://dx.doi.org/10.1016/j.techfore.2008.09.001

Silva, A.; Afonso, O.; Africano, A. P. 2013. Economic performance and international trade engagement: the case of portuguese firms, International Economics and Economic Policy 10(4): 521-547. http://dx.doi.org/10.1007/s10368-012-0221-8

Thompson, V. 1965. Bureaucracy and innovation, Administrative Science Quarterly 10: 1-20. http://dx.doi.org/10.2307/2391646

Werker, C. 2003. Innovation, market performance, and competition: lessons from a product life cycle model, Technovation 23: 281-290. http://dx.doi.org/10.1016/S0166-4972(01)00109-2 
Jurriën J. BAKKER (25) has obtained a Bsc in Applied Physics and a Msc in Innovation Sciences at Eindhoven University of Technology. He has completed an Erasmus semester in Business and Innovation at the Faculty of Economics, University of Porto. He is currently a PhD student at the faculty of applied economics Catholic University of Leuven.

Oscar AFONSO (44) has obtained MA and PhD degrees in Economics from the University of Porto. $\mathrm{He}$ is Assistant Professor at Faculty of Economics, University of Porto, and researcher at CEFUP (Center in Economics and Finance), OBEGEF (Observatory in Economics and Management of Fraud) and NIFIP. He has published a book, book chapters and articles in Acta Oeconomica, Advances in Management and Applied Economics, Applied Economics, Applied Economics Letters, Economic Modelling, Economics Letters, Ekonomiaz, Economics Research International, Energy Journal, European Research Studies Journal, Intereconomics, International Economic Journal, International Trade Journal, Japanese Economic Review, Journal of Business Economics and Management, Journal of International Trade and Economic Development, Macroeconomic Dynamics, Manchester School, Metroeconomica, Open Business Journal and Review of World Economics. He has been teaching Computational Economics (Doctoral Program in Economics), Economic growth (Master and Doctoral Program in Economics), Macroeconomics (Undergraduate Economics) and International trade (Undergraduate Economics).

Sandra T. SILVA (39) is Assistant Professor at Faculty of Economics, Porto University (FEP) and researcher at CEFUP (Center in Economics and Finance). She holds a MA and a PhD, both in Economics, from FEP. She has published a pedagogic book on macroeconomics, some book chapters and articles related with evolutionary economics, innovation and economic growth, published in international journals such as Journal of Evolutionary Economics, Journal of Economic Interaction and Coordination, Evolutionary and Institutional Economics Review, Organisational Transformation and Social Change. Current research interests are on evolutionary economics, innovation, economic growth, poverty and inequality. She has been teaching several courses at FEP, for example, Macroeconomics (Undergraduate Economics, Master in Economics and Doctoral Programme in Economics), Economic Growth (Undergraduate Economics), and Theories and Systems of Innovation (Master in Innovation Economics and Management). 